\title{
BUCKLING AND POST-BUCKLING OF PRESTRESSED STAINLESS STEEL STAYED COLUMNS
}

\author{
Radek PICHAL ${ }^{\mathrm{a}}$, Josef MACHACEK ${ }^{\mathrm{b}}$ \\ Department of Steel and Timber Structures, Faculty of Civil Engineering, Czech Technical University \\ in Prague, Thakurova 7, 16629 Prague, Czech Republic
}

Received 08 November 2016; accepted 23 December 2016

\begin{abstract}
Prestressed stayed compression members are frequently required as very slender load-bearing structural components by both investors and architects. Behavior of these members depends on their geometrical and material properties, prestressing and boundary conditions. In the paper are discussed respective critical buckling loads and post-buckling paths with regards to 2D and 3D GMNIA (geometrically and materially nonlinear analysis with imperfections) using ANSYS software. Former tests and recent detailed analyses of other authors are commented with respect to the 3D analysis, level of imperfections, boundary conditions at central crossarm (fixed or sliding stays) and nonlinear stainless steel material.
\end{abstract}

Keywords: prestressed stayed columns, nonlinear buckling, finite element modelling, 3D analysis, nonlinear material, sliding stays.

\section{Introduction}

Very slender compression elements are often required as the visual architectonic components, but their slenderness limits both critical (buckling) loading and design load (strength). Application of prestressed steel stayed columns provides substantial increase of these values at the cost of rather higher expenses for fabrication and assembly, and may also affect aesthetics of the structure (Fig. 1).

The stayed columns are usually formed by central steel tube of length $L$, mid-span crossarm with 4
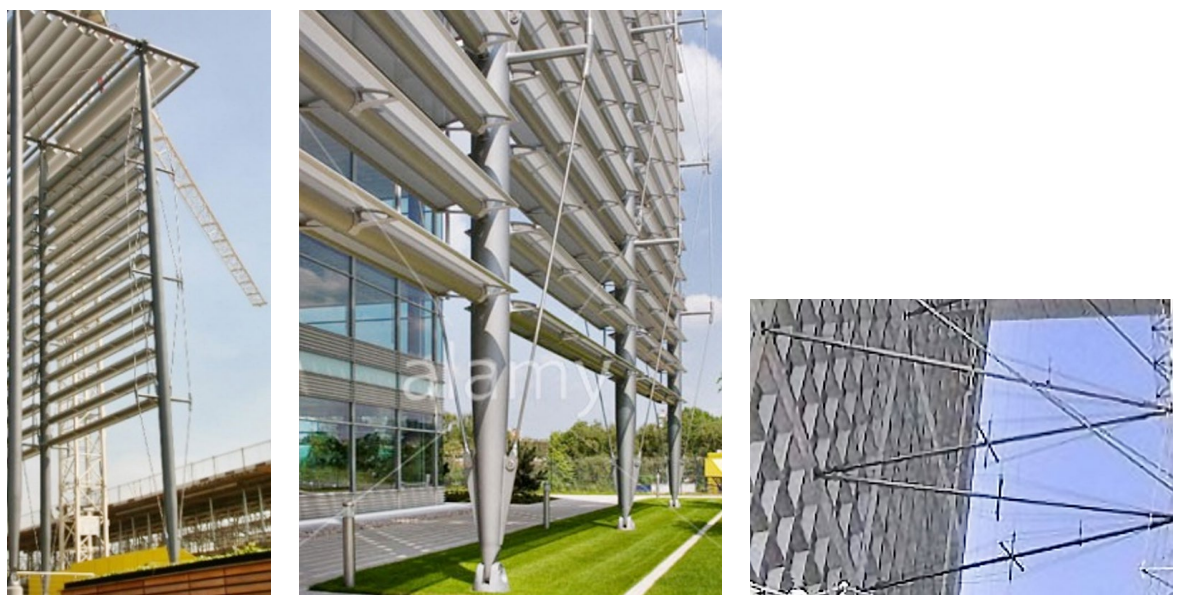

Fig. 1. Stayed members in London (left and middle), supports of Grande Arche lift in Paris

Corresponding author:

R. Pichal E-mail: radek.pichal@fsv.cvut.cz 
arms of length $a$ in angle $\alpha=90^{\circ}$ and stays made of cables or rods, each with prestress $T$. However, common are also stayed columns with two, three or more crossarms along the span $L$ in planar (crossarm with 2 arms in angle $\alpha=180^{\circ}$ ) or triple (with angle $\alpha=$ $120^{\circ}$ ) arrangements. The basic setup shown in Figure 2 was analyzed analytically by Smith et al. (1975) and Hafez et al. (1979), resulting in principal determination of formulas for buckling loads under arbitrary stay prestress and also „optimal” prestress $T_{o p t}$, giving maximal buckling load $N_{c r, m a x}$. Influence of initial deflections was studied by Wong and Temple (1982), Chan et al. (2002) and completely by Saito and Wadee (2009), showing predominant buckling modes with respect to ratio $2 a / L$, stay area $A_{s}$, and shape of initial deflections (respective modes are shown in Figure 2. The stayed columns were also tested experimentally e.g. by Hafez et al. (1979), Araujo et al. (2008), Servitova and Machacek (2011) and Osofero et al. (2012), the last one revealing the post-buckling behavior of imperfect stayed columns depending on critical modes and level of prestress.

The post-buckling behavior was studied using geometrically nonlinear model and Ritz energy formulation by Saito and Wadee (2008), validated by FEM (ABAQUS software). The results cleared up the stable or unstable paths of column behavior after buckling in both symmetric and antisymmetric buckling modes, followed by recommendation to determine design loading according to prestress values rather than buckling loads.

Recent parametrical study by Wadee et al. (2013) followed the imperfection study (Saito, Wadee 2009) and FEM model (Saito, Wadee 2008). Vast study introduced three levels of global column initial deflections ( $L / 1000, L / 400, L / 200$ ), various ratios $2 a / L$ (to cover all possible buckling modes) and initial stay prestress up to $3 T_{o p t}$. The maximum load-carrying capacity $N_{\max }$ was then established by GNIA and respecting test results. The formulae of ratio $N_{\max } / N_{c r}$ for direct use in design are presented and partial safety factor $\gamma_{M 1}=$ 1 recommended. The simplified graphical presentation of these results is shown in Figure 3, where critical load on vertical axis follows formulation by $\mathrm{Hafez}$ (Hafez et al. 1979).

All former analytical and numerical studies concerned elastic nonlinear 2D analysis, possibly extended for influence of 4 space arms/stays of the space perpendicular crossarm but with buckling in the direction of the arms. The connections between the stays, columns and the crossarm were assumed to be ideal hinges.

The present paper deals with the $3 \mathrm{D}$ behavior of the stayed columns using GMNIA (geometrically and

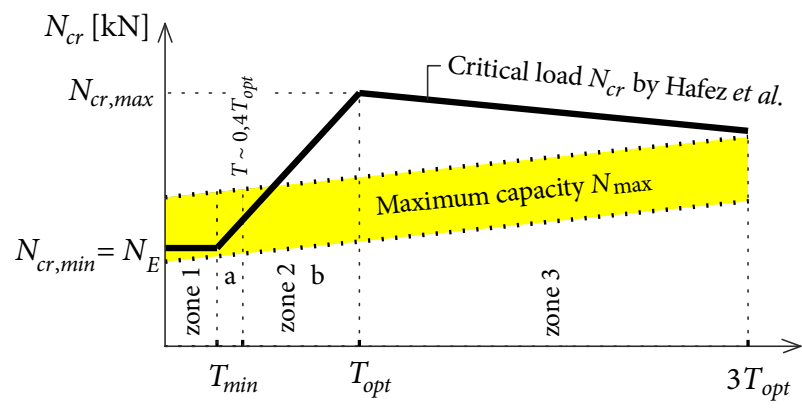

Fig. 3. Maximum load-carrying capacities $N_{\max }$ for stayed columns with respect to critical buckling loads $N_{c r}$ versus the initial prestress $T$ according Wadee et al. (2013)
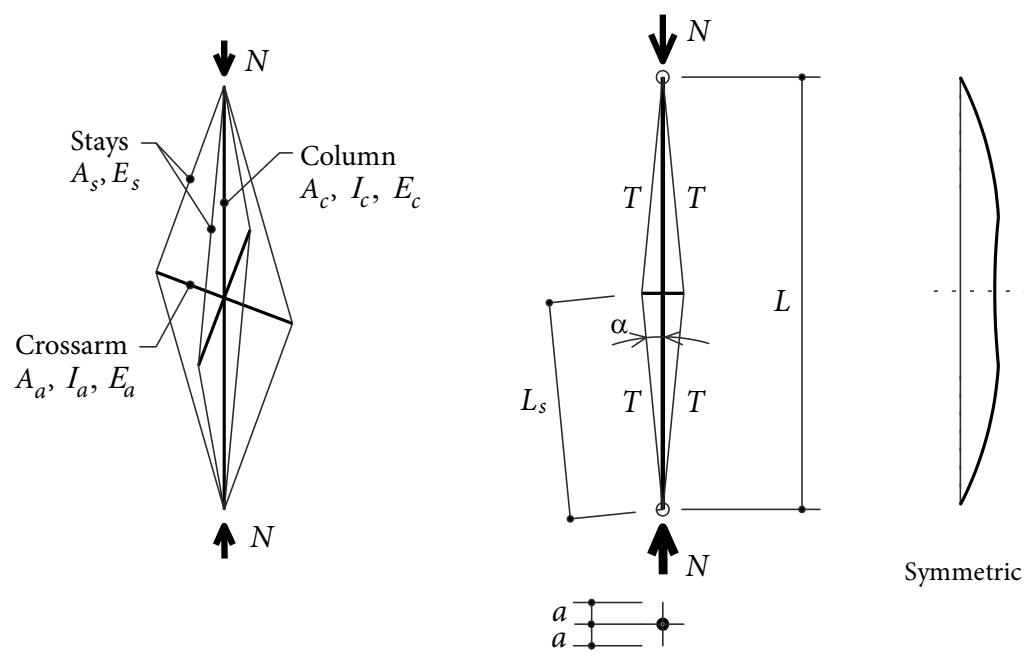

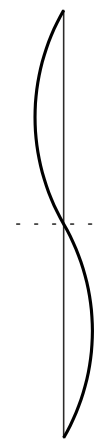

Buckling modes

Antisymmetric Interactive

Fig. 2. Stayed column in basic set-up (left), geometry of analysis (right) 
materially nonlinear analysis with imperfections) with respect to dissimilarity of $2 \mathrm{D}$ and $3 \mathrm{D}$ behavior. Also stays sliding on the crossarm which may be advantageous from assembly point of view and material nonlinearity typical in stainless steel stayed columns are analyzed.

\section{3D critical buckling loads of stayed columns}

Analytical analysis of the critical load and optimal prestress for a stayed column with a single crossarm according to Smith et al. (1975) and Hafez et al. (1979) is provided for convenience in the Appendix. Resulting relation of buckling loads versus initial stay prestressing was derived for planar buckling of stayed columns (in the direction of the crossarms), similarly as other numerical analyses mentioned in the Introduction. Nevertheless, the space stayed columns in tests buckled into the direction between the arms of the crossarm (Servitova, Machacek 2011), where the stiffness is minimal. Therefore, the $3 \mathrm{D}$ solution using ANSYS software was employed to assess the difference towards the $2 \mathrm{D}$ analysis.

The column under investigation has the following parameters (span $L$, cross-section area $A$, second moment of area $I$, Young's modulus $E$ ):

- tube column $\varnothing 50 \times 2[\mathrm{~mm}]: L=5000 \mathrm{~mm}, A_{c}=$ $301.59 \mathrm{~mm}^{2}, I_{c}=87009,6 \mathrm{~mm}^{4}, E_{c}=200000$ $\mathrm{MPa}$,

- crossarm tube $\varnothing 25 \times 1.5[\mathrm{~mm}]: a=250 \mathrm{~mm}$, $A_{a}=110.74 \mathrm{~mm}^{2}, I_{a}=7675.7 \mathrm{~mm}^{4}, E_{a}=200000$ $\mathrm{MPa}$,

- cable Macalloy stay $\varnothing 4 \mathrm{~mm}: L_{s}=2513 \mathrm{~mm}$, $A_{s}=12.57 \mathrm{~mm}^{2}, E_{s}=200000 \mathrm{MPa}$.
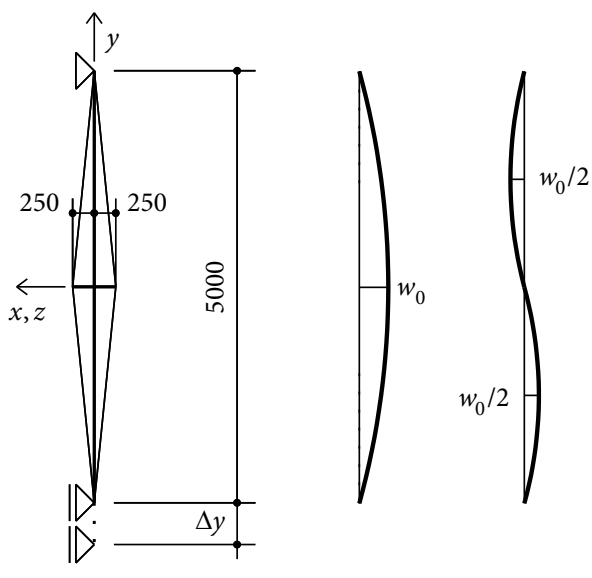

Analytical analysis according to formulas given in the Appendix provides the following results:

- Euler's critical buckling load of the column without stays $N_{c r}=6.87 \mathrm{kN}$,

- maximal critical load of the stayed column with symmetrical buckling $N_{c r \text { max }, \text { sym }}=39.78 \mathrm{kN}$,

- maximal critical load of the stayed column with antisymmetrical buckling $N_{c r, \text { max, anti }}=36.79 \mathrm{kN}$, - optimal prestress $T_{o p t}=1.302 \mathrm{kN}$.

Numerical ANSYS modeling use the following finite elements:

- column and crossarm tubes: BEAM188 (3D, $2 \times 6=12 \mathrm{DOF}$, large deflections, material nonlinearity),

- cable stays: LINK180 (3D, $2 \times 3=6 \mathrm{DOF}$, large deflections, material nonlinearity, introduced tension only),

- saddle at crossarm (in case of sliding stays): SHELL281 (3D, $8 \times 6=48$ DOF, large deflections, material nonlinearity).

The prestressing was introduced by the stay's thermal change and external loading by axial column displacement $\Delta y$. The respective prestressing loads and external column loading values were recalculated from the column reactions. Numerical procedure employed arc-length method to allow for unloading path (see Fig. 4).

To analyze critical loads of the prestressed stayed column for the full range of prestress values the geometrically nonlinear analysis (GNIA) is necessary, as revealed by Saito and Wadee (2008). If the prestress is small (zone 1) the tension in the stays under column loading disappears before the loading reaches the buckling (Euler's) load. With greater prestressing

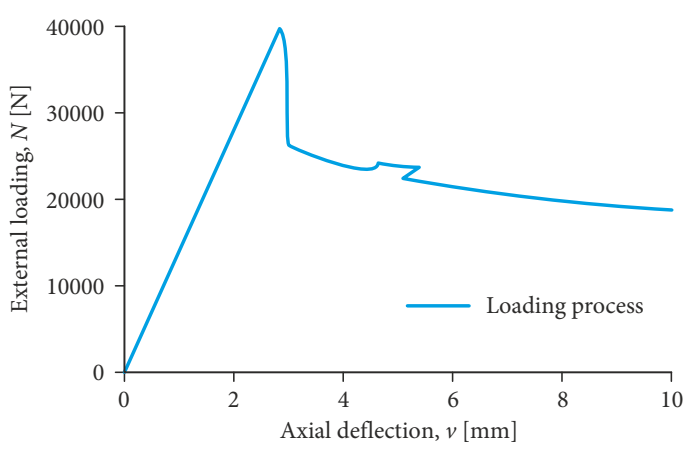

Fig. 4. Initial deflections (symmetrical and antisymmetrical mode, left) and a load-deflection path for optimal prestressing (right). 
(zone 2) the stays remain effective (tensioned) up to instant of buckling. Afterwards the stays on the concave side become slack, giving higher than Euler's buckling load, necessary to be solved by nonlinear bifurcation analysis only. With large stay prestressing (zone 3 ) the stays remain effective (tensioned) for some time even after buckling.

Using GMNIA the introduction of initial deflections is necessary. The two decisive buckling modes were considered, shown in Figure 4 . The amplitudes $w_{0 x}=w_{0 z}$ were introduced in both arm directions (i.e. in the $3 \mathrm{D}$ space the amplitude value was $w_{0} \sqrt{2}$ ) and the sensitivity of the critical load on the amplitude were analyzed (just for symmetrical initial deflections) using $w_{0}=L / 500000=0.01 \mathrm{~mm}$ (simulating ideal straight column), $w_{0}=0.05 \mathrm{~mm}, w_{0}=0.1 \mathrm{~mm}$.

\subsection{Stays hinged to the crossarm}

The stayed column in its basic arrangement employs fixed hinged connections of the stays to the crossarm. The 3D GNIA results are shown in Figure 5. Comparison of the 3D maximal critical values together with analytical 2D solution is presented in the Table 1 . The final buckling mode for the given arrangement corresponds always to the introduced initial deflection shape, except of cases with antisymmetrical initial deflections and of small prestress $(<0.47 \mathrm{kN})$.

The 3D GNIA with the small initial deflections give nearly identical critical loads as the $2 \mathrm{D}$ analytical analysis. Negligible differences may arise due to the imperfections, non-rigid crossarm and space buckling.

The space buckling is demonstrated in Figure 6, showing a stayed column with a predominant symmetrical initial deflection in the direction of plane $y-z$ $\left(w_{0 x}=0.01 \mathrm{~mm} ; w_{0 z}=5 \mathrm{~mm}\right)$. The column midspan deflection with increase of loading follows direction of the greater initial one and later traverse into space deflection, up to the buckling load value. The instant of change of the direction into the space depends on the value of prestress: the greater prestress, the higher value of the instant of change. Such conclusion results from numerical analyses of several examples with various prestress and imperfections values. Loss of prestress in the stays is also shown in Figure 6.

\subsection{Stays sliding on the crossarm}

Modelling of sliding stays requires use of shell elements and introduction of friction (coefficient $v$ ) at the saddle-stay interface. Comparison of results with the friction $v=0.1$ and $w_{0}=0.01 \mathrm{~mm}$ are given in Figure 7 .

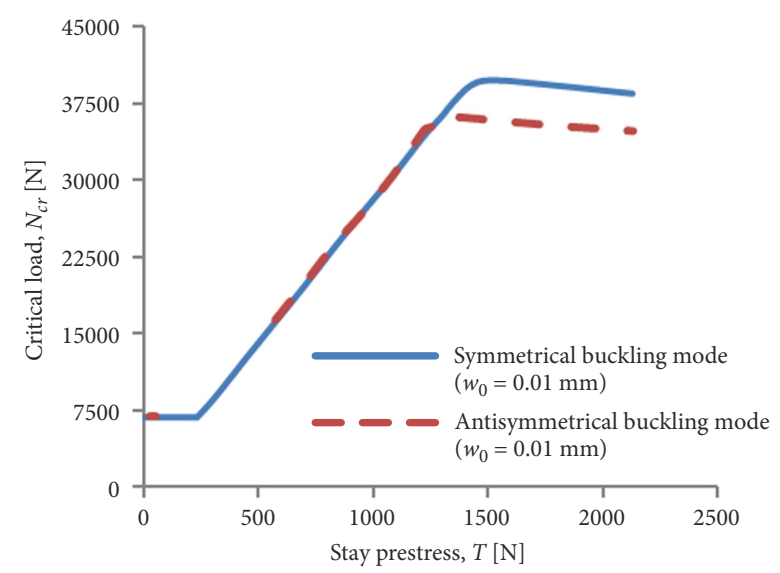

Fig. 5. Critical load versus prestress (per one stay) for symmetrical buckling mode (left) and comparison with antisymmetrical mode (right)

Table 1. Maximal critical loads and optimal prestressing

\begin{tabular}{|c|c|c|c|c|c|}
\hline \multirow[b]{2}{*}{$\begin{array}{c}\text { Initial deflection, } \\
w_{0}[\mathrm{~mm}]\end{array}$} & \multicolumn{2}{|c|}{ Symmetrical initial deflections } & \multicolumn{2}{|c|}{ Antisymmetrical initial deflections } & \multirow[b]{2}{*}{$\begin{array}{c}\text { Decisive, } \\
N_{c r, \text { max }}[\mathrm{kN}]\end{array}$} \\
\hline & $\begin{array}{c}\text { Optimal prestressing, } \\
T_{\text {opt }}[\mathrm{kN}]\end{array}$ & $\begin{array}{l}\text { Maximal critical load, } \\
N_{c r, \max , \text { sym }}[\mathrm{kN}]\end{array}$ & $\begin{array}{c}\text { Optimal prestressing, } \\
T_{o p t}[\mathrm{kN}]\end{array}$ & $\begin{array}{l}\text { Maximal critical load, } \\
\quad N_{c r, \text { max,anti }}[\mathrm{kN}]\end{array}$ & \\
\hline 0 (acc. [2], 2D) & 1.41 & 39.79 & 1.30 & 36.79 & 36.79 \\
\hline 0.01 & 1.51 & 39.73 & 1.35 & 36.18 & 36.18 \\
\hline 0.05 & 1.58 & 39.25 & - & - & - \\
\hline 0.10 & 1.61 & 38.62 & - & - & - \\
\hline
\end{tabular}


While maximal critical loads for the symmetrical buckling mode are nearly identical with values for fixed stays, in the case of sliding stays the antisymmetrical buckling gives much lower values (see Fig. 7 right, and compare with Fig. 5). This is due to sliding of stays after breaking the friction and restoring equilibrium in the stays.

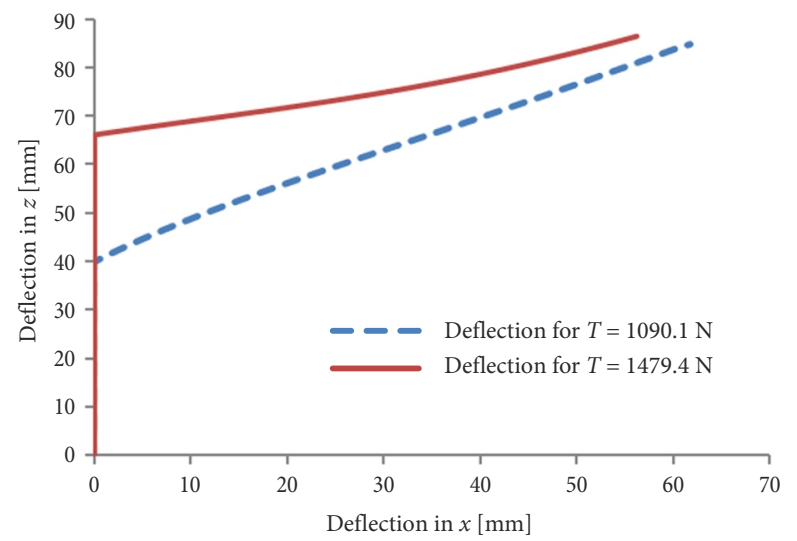

\subsection{Effect of the material nonlinearity}

In tests by Servitova and Machacek (2011) the tubes of column and crossarm were made of austenitic stainless steel 1.4301. The stress-strain relationship of the material was received from the whole tube tension tests and the average values introduced as multilinear isotropic material into ANSYS analysis (GMNIA) according to Figure 8.

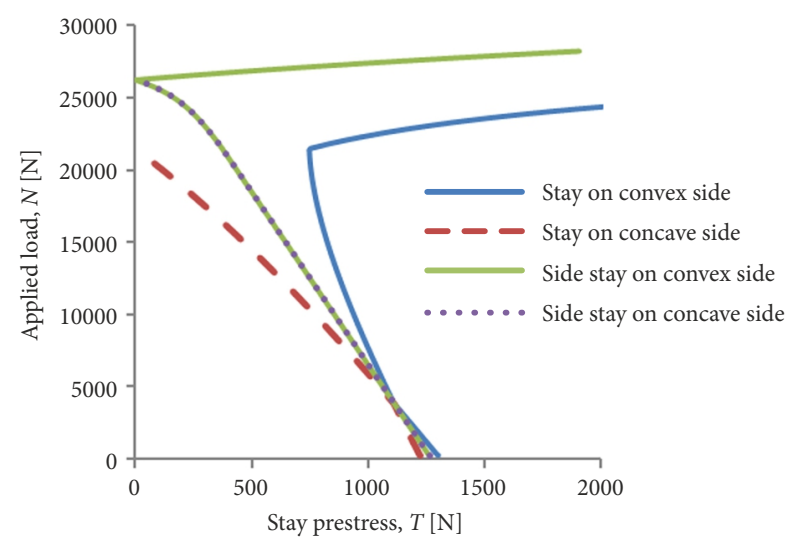

Fig. 6. The space buckling of initially symmetrically deflected column $\left(w_{0 x}=0.01 \mathrm{~mm} ; w_{0 z}=5 \mathrm{~mm}\right)$ and loss of prestress in the stays
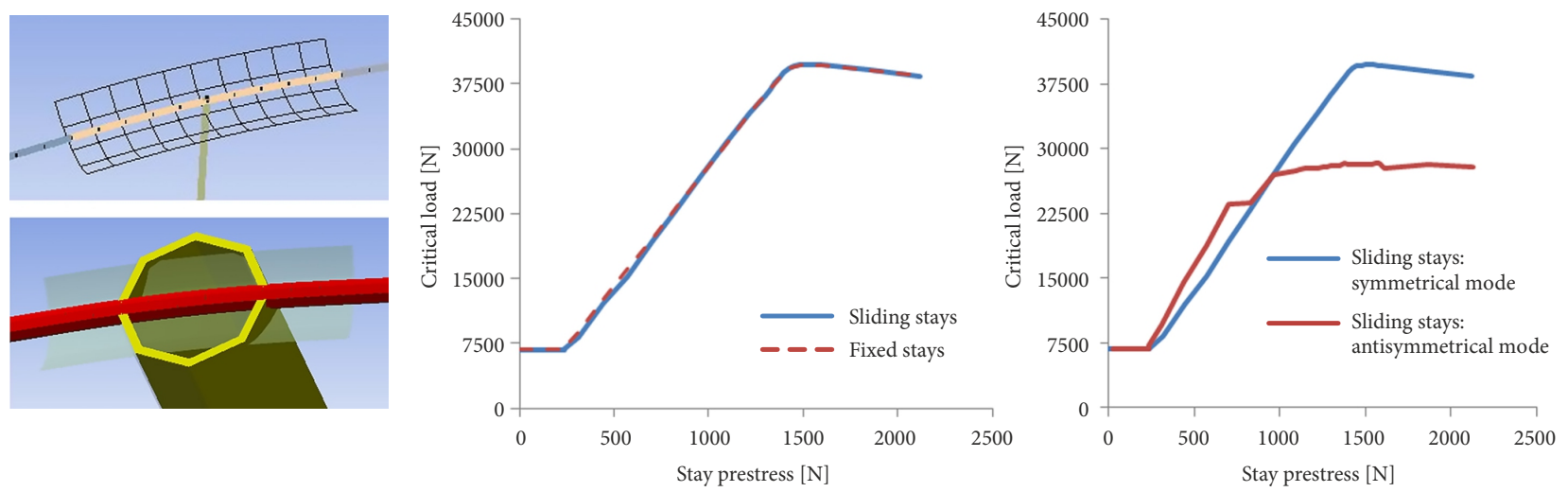

Fig. 7. Sliding saddle FE modeling (left), $N_{c r s y m}$ for fixed and sliding stays (middle), for sliding stays $N_{c r, s y m}$ and $N_{c r, a n t i}$ (right)
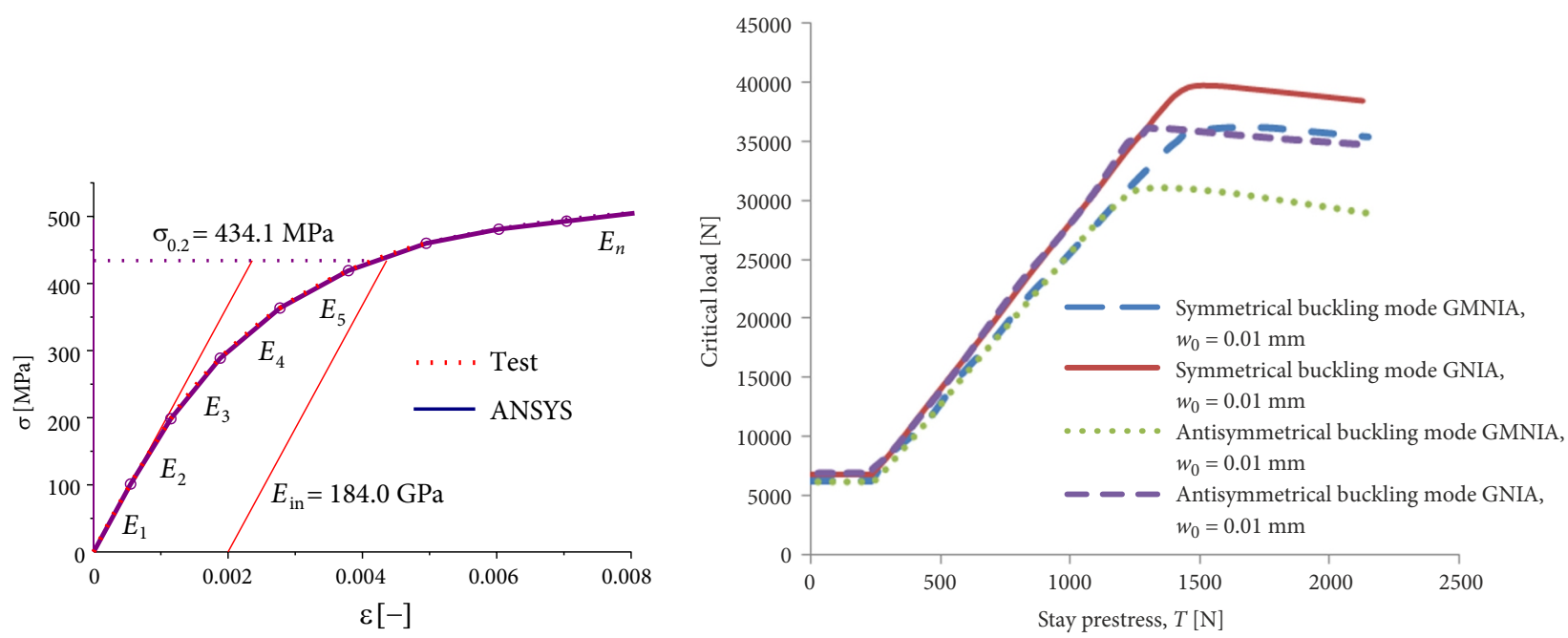

Fig. 8. Stress-strain relationship for austenitic steel 1.4301 (left), results of GNIA and GMNIA (right) 
However, because the stress at the maximal critical load is rather low (< 132 MPa), the $N_{\text {crmax }}$ in comparison with formerly introduced steel (constant $E=$ $200 \mathrm{GPa}$, while here $E_{1}=184 \mathrm{GPa}, E_{2}=161 \mathrm{MPa}$ ) are lower roughly according to ratios of these modules (ANSYS gives GNIA/GMNIA ratio in symmetrical mode 0.91 , in antisymmetrical mode 0.86 ).

\section{Conclusions}

- GNIA in 3D proved buckling of the prestressed stayed columns in the space (between the arms). Nevertheless, the 2D critical loads received for the buckling in the direction of the arms gives nearly identical values.

- Amplitudes of initial deflections $\left(w_{0}\right)$ using 3D GNIA affect substantially the buckling behavior and value of the respective critical load $N_{c r}$. From the sensitivity study the values $w_{0} \leq L / 500000$ may well be recommended for calculation of the bifurcation load corresponding to LBA.

- Stays sliding on the crossarm with friction $v=0.1$ and symmetrical buckling mode give nearly identical critical loads as for the fixed stays for various prestressing in all zones 1, 2, 3 including $N_{c r \text { max }}$. Nevertheless, in antisymmetrical buckling mode the critical loads are substantially lower. The required values of friction needed to keep the critical load the same as for fixed stays is still under investigation.

- Stainless steel with respect to material nonlinearity requires proper introduction of the stress-strain relationship.

\section{Funding}

Support of the Czech Technical University in Prague and grant of the Czech Grant Agency GACR No. 1724769 S is gratefully acknowledged.

\section{References}

Araujo, R. R.; Andrade, S. A. L.; Vellasco, P. C. G. S.; Silva, J. G. S.; Lima, L. R. O. 2008. Experimental and numerical assessment of stayed steel columns, Journal of Constructional Steel Research 64: 1020-1029.

https://doi.org/10.1016/j.jcsr.2008.01.011

Chan, S. L.; Shu, G.; Lü, Z. 2002. Stability analysis and parametric study of pre-stressed stayed columns, Engineering Structures 24(1): 115-124.

https://doi.org/10.1016/S0141-0296(01)00026-8

Hafez, H. H.; Temple, M. C.; Ellis, J. S. 1979. Pretensioning of single-crossarm stayed columns, Journal of the Structural Division ASCE 14362(ST2): 359-375.
Osofero, A. I.; Wadee, M. A.; Gardner, L. 2012. Experimental study of critical and post-buckling behaviour of prestressed stayed steel columns, Journal of Constructional Steel Research 79: 226-241. https://doi.org/10.1016/j.jcsr.2012.07.013

Saito, D.; Wadee, M. A. 2008. Post-buckling behaviour of prestressed steel stayed columns, Engineering Structures 30: 1224-1239. https://doi.org/10.1016/j.engstruct.2007.07.012

Saito, D.; Wadee, M. A. 2009. Numerical studies of interactive buckling in prestressed steel stayed columns, Engineering Structures 31: 432-443. https://doi.org/10.1016/j.engstruct.2008.09.008

Servitova, K.; Machacek, J. 2011. Analysis of stainless steel stayed columns, in: 6th International Symposium of Steel Structures, 3-5 November 2011, Seoul, Korea. Korean Society of Steel Construction, 874-881.

Smith, R. J.; McCaffrey, G. T.; Ellis, J. S. 1975. Buckling of a single-crossarm stayed column, Journal of the Structural Division ASCE11071(ST1): 249-268.

Wadee, M. A.; Gardner, L.; Osofero, A. I. 2013. Design of prestressed stayed columns, Journal of Constructional Steel Research 80: 287-298. https://doi.org/10.1016/j.jcsr.2012.09.021

Wong, K. C.; Temple, M. C. 1982. Stayed columns with initial imperfections, Journal of the Structural Division ASCE 108(ST7): 1623-1640.

\section{Appendix}

Analytical analysis by Smith et al. (1975) and Hafez et al. (1979) covers bifurcation of a stayed column with single crossarm in the mid-span (Fig. 2) and resulted into relation critical load vs initial prestress as shown in Figure A1.

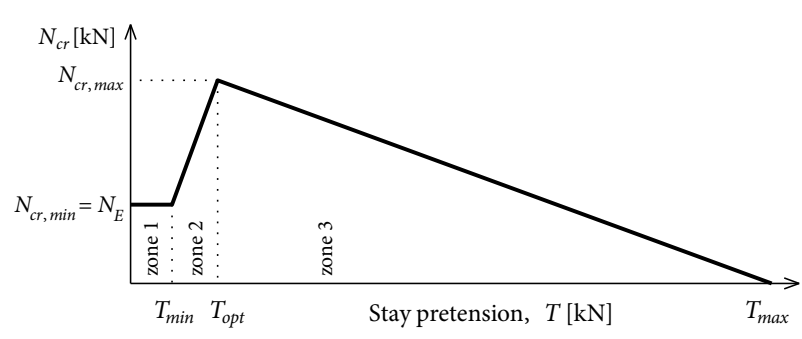

Fig. A1. Initial stay prestress (per stay) versus buckling load of the column

The cross-sectional area, second moment of area and Young's modulus of the column (with length $L$ ) are $A_{c}\left[\mathrm{~mm}^{2}\right], I_{\mathrm{c}}\left[\mathrm{mm}^{4}\right], E_{c}[\mathrm{MPa}]$, of the crossarm member (with length $a$ ) are $A_{a}\left[\mathrm{~mm}^{2}\right], I_{\mathrm{a}}\left[\mathrm{mm}^{4}\right], E_{a}$ [MPa] and of the stays (with length $L_{\mathrm{s}}$ ) are $A_{s}\left[\mathrm{~mm}^{2}\right]$, $E_{s}[\mathrm{MPa}]$. Then

$$
K_{c}=\frac{E_{c} A_{c}}{L}[\mathrm{~N} / \mathrm{mm}], B_{c}=\frac{8 E_{c} I_{c}}{L^{3}}[\mathrm{~N} / \mathrm{mm}]
$$

are the column axial and bending stiffness. 


$$
K_{a}=\frac{E_{a} A_{a}}{a}[\mathrm{~N} / \mathrm{mm}], B_{a}=\frac{E_{a} I_{a}}{a^{3}}[\mathrm{~N} / \mathrm{mm}]
$$

are the crossarm axial and bending stiffness.

$$
K_{s}=\frac{E_{s} A_{s}}{L_{s}}[\mathrm{~N} / \mathrm{mm}]
$$

is the stay axial stiffness.

Zone 1: The prestress is very low $\left(T<T_{\text {min }}\right)$ so that tension in the stays disappears, column behaves as an unstayed column and buckling load equals to the Euler load $N_{c r \text { min }}=N_{E}$. For the prestress in which the tension disappears yields:

$$
C_{1}=\frac{T_{\min }=C_{1} N_{E} ;}{2 K_{c}\left(\frac{1}{K_{s}}+\frac{2 \sin ^{2} \alpha}{K_{a}}+\frac{n \cos ^{2} \alpha}{2 K_{c}}\right)} .
$$

For space crossarm (4 stays) $n=4$, for planar arrangement ( 2 stays) $n=2$.

Zone 2: The prestress is larger than the minimum one $\left(T_{\min }\right)$, but equal or less than the optimum one $\left(T_{o p t}\right)$, in which the buckling load reaches its maximum value $N_{c r \text { max }}$. The prestress in the stays is active (non-zero) up to instant of buckling. The buckling load in this zone is given by

$$
N_{c r, 2}=\frac{T}{C_{1}} .
$$

Zone 3: The prestress is greater than optimum one $\left(T_{o p t}\right)$. The stays remain active (tensioned) yet after buckling. The prestress in the stays increases the column loading and consequently decreases the buckling load of the column. The maximum possible prestress, causing buckling of the column itself without any applied load, is given by

$$
T_{\max }=\frac{N_{c r, \max }}{n \cos \alpha} .
$$

The column buckling load in this zone may be obtained from:

$$
\begin{aligned}
& N_{c r, 3}=\left(N_{c r, \text { max }}-n T \cos \alpha\right) C_{2} ; \\
& C_{2}=1+\frac{n \cos ^{2} \alpha}{2 K_{c}\left(\frac{1}{K_{s}}+\frac{2 \sin ^{2} \alpha}{K_{a}}\right)} .
\end{aligned}
$$

Determination of the maximum buckling load $N_{c r \text { max }}$ depends on the buckling mode (Fig. 2) and follows from solution of goniometric equations for value of $k l$ given by

$$
k l=\frac{L}{2} \sqrt{\frac{N}{E_{c} I_{c}}} .
$$

For symmetric mode of buckling the equation is as follows:

$$
\frac{2 K_{s}}{B_{c}} \sin ^{2} \alpha=\frac{(k l)^{3}}{k l-\operatorname{tg} k l} .
$$

For antisymmetric mode of buckling the equation is given by

$$
\frac{B_{c}}{\sin ^{2} \alpha}\left(\frac{\cos ^{2} \alpha}{3 B_{a}}+\frac{1}{2 K_{s}}\right)=\frac{k l-\operatorname{tg} k l}{(k l)^{2} \operatorname{tg} k l} .
$$

The maximum possible buckling load (Fig. A1) follows from minimum value of $k l\left(k l_{\text {min }}\right.$ corresponding to the decisive buckling mode) and from eq. (A8) yields:

$$
N_{c r, \max }=\frac{4\left(k l_{\min }\right)^{2} E_{c} I_{c}}{L^{2}} .
$$

Corresponding optimum prestress per stay is given by

$$
T_{o p t}=N_{c r, \max } C_{1}
$$

Radek PICHAL. PhD student under supervision of Professor Machacek. He graduated from Faculty of Civil Engineering of the Czech Technical University in Prague and intends to submit PhD thesis on Stainless Steel Prestressed Stayed Columns. Parallel, He works like a engineer in civil engineering.

Josef MACHACEK. Professor at Faculty of Civil Engineering of the Czech Technical University in Prague (Czech Republic). He published more than 300 research papers and teaching books on stability and elastic-plastic strength of thin steel plates, progressive thin-walled steel and stainless steel elements, composite steel and concrete structures and textile membranes cooperating with steel structures (see http://people.fsv.cvut.cz/ machacek/). 